\title{
BIOCHEMICAL DISTURBANCES AFTER TRANSPLANTATION OF THE URETERS
}

\author{
By A. W. Wilkinson, Ch.M., F.R.C.S. (Edin.) \\ Senior Lecturer in Surgery, University of Aberdeen
}

Complete diversion of the urinary flow to the large bowel was first deliberately achieved in $185 \mathrm{I}$ by Simon, who produced fistulae between the lower ends of the ureters and the rectum in a boy aged 13 years who had extroversion of the bladder, the patient survived for 10 months and died of the effects of infection; accidental fistulous connection between the bladder and bowel may not have been uncommon before this time following perineal lithotomy. During the ensuing roo years thousands of patients have had their ureters transplanted by more than 80 different techniques, the chief indications being congenital anomalies such as extroversion of the urinary bladder, some forms of vesical fistulae and tuberculosis or carcinoma of the bladder.

The reduction of infective complications following the introduction of the sulphonamide and antibiotic drugs and improvements in anaesthesia, blood transfusion and other types of fluid therapy led to a marked reduction in the early mortality and morbidity following this operation. It was recognized many years ago that patients who survived the operation for more than six months or a year were liable to suffer from recurrent bouts of fever with loss of appetite, nausea and tiredness. It has become increasingly evident that such disturbances cannot always be ascribed to ascending infection and pyelonephritis and that a significant part of the late post-operative disturbances have a chemical basis.

Until recently indirect anastomosis by either the Coffey (I9II) or Stiles (I9II) method was by far the commonest procedure; in this a length of ureter is laid in a tunnel made in the wall of the pelvic colon with the distal end of the ureter projecting into the lumen of the colon. This results in a valvular formation, but the lower end of the ureter is liable to stenosis and the formation of calculi and concretions, with hydronephrosis and dilatation of the ureter. During the last six years a direct anastomosis of the Nesbit (1949) type, in which the mucosa of the ureter is sutured to that of the colon, has been employed more frequently. The disadvantage of this method is that there may be reflux of gas and faecal fluid from the colon up the ureter.

After transplantation all the urine is discharged into the colon and for up to a week after operation the bowel is drained through an indwelling rectal tube; most patients become continent soon after removal of this tube. Subsequently they are able to distinguish between fluid and solid contents and they empty the bowel at varying intervals of from 2 to 5 hours during the day and rise once or twice during the night. The combined output of water in urine and faeces is increased after this operation and the daily consumption of water rises.

The typical biochemical disturbance is usually found in continent patients after complete diver:o sion of their urine to the colon; it may come on at any time after operation, but appears to become commoner the longer the patient survives operation and when renal function is impaired. The commonest type of disturbance is an elevation of the plasma chloride concentration which is usually accompanied by depression of the plasma bicarbonate concentration, the so-called 'hyperchloraemic acidosis'. Flocks (1949) found mild to moderate acidosis in 62 per cent. of patients after bilateral ureterosigmoidostomy. Ferris and Odel (1950) reviewed I4I patients and found that in 79 per cent. the plasma chloride concentration was above normal, and that in 75 per cent. this had occurred within a year of operation; in 80 per cent. plasma bicarbonate was below the normal range and this had occurred within a year of operation in 77 per cent. Two-stage transplantations were done in 16 of their patients, the plasma chloride concentration was raised in two and bicarbonate was lowered in five patients after only one ureter had been transplanted. Jacobs and Stirling (1952) found that six months or more after bilateral ureterosigmoidostomy there was depression of plasma concentrations of bicarbonate in 81 per cent. and of potassium in 30 per cent., and elevation of plasma concentrations of chloride in 48 per cent., urea in 76 per cent., and sodium in less than ro per cent. of the patients on 
whom these observations were made. Contrary to the belief of Flocks and of Foster, Drew and Wiss that the tendency to acidosis disappears after six months from operation, Jacobs and 'Stirling found that there was a progressive increase in the incidence and severity of the abnormality of the bicarbonate, chloride and urea concentrations as time elapsed, and that acidosis and retention of urea were more common in patients whose renal function was poor.

Most of the patients show similar clinical features. At first they are easily tired or feel weak and their appetite becomes poor; later there may be nausea with revulsion for food and vomiting, irritability and increasing drowsiness. From an early stage they notice a salty taste in their mouths, later thirst becomes progressively more severe. Most of them experience rectal urgency and frequency and the rectal fluid is unusually watery and its volume is increased. Not all conform to this pattern and it is noteworthy that some patients may show severe distortion of their blood chemistry without experiencing any symptoms or alteration in fluid intake or output.

Diefenbach, Fisk and Gibson (195I) drew attention to the possible importance of potassium deficiency in this syndrome when they reported the case of a man whose presenting feature was a complete flaccid quadriplegia with an associated low serum potassium concentration sixteen months after bilateral transplantation of the ureters to the colon; in this case there was little alteration in plasma bicarbonate, chloride or urea concentrations and there was a rapid response to the intravenous administration of Darrow's solution. Foster, Drew and Wiss (r950) had already reported a patient of theirs who, following two premonitory disturbances marked by hiccup and acidosis, was admitted atter rigors, anorexia and weakness in a semi-conscious state with a low serum potassium concentration. Further cases of severe potassium deficiency complicating acidosis have been reported by Wilkinson (1952), Parsons et al. (1952) and Creevy (1953). Amongst these patients both the morbidity and mortality rates are higher; even when the potassium deficiency is recognized and specially treated, recovery is slower and complications are more common.

Anuria is not a common feature of the chemical disturbances after ureterosigmoidostomy and is usually associated with severely damaged kidneys (Parsons et al., 1952) or with advanced potassium deficiency (Wilkinson, 1952).

In the majority of patients rapid relief of symptoms follows such simple measures as continuous drainage of the rectum by an indwelling tube or washing out the large bowel repeatedly with water combined with the consumption of a normal fulfू diet (Ferris and Odel, 1950). Even the disordered blood chemistry returns to within normal limits in most cases if rectal drainage is continued forfour or five days. Relief has also been obtained after unilateral nephrostomy or by caecostomy:? Intravenous therapy seems seldom to have been? necessary, except in cases complicated by sever $\frac{0}{\bar{n}}$ potassium deficiency, but when patients are semi $\frac{\text { त }}{\widetilde{T}}$ conscious or comatose, prompt relief usually $\varrho$ depends on the early intravenous administrations of potassium salts. In most cases it is enough to increase the fluid intake by persuading the patients to drink up to six pints each day.

Prevention of the disturbance has been attemp $\frac{\text { क }}{8}$ ted by various measures and it is difficult to judge how effective some of these have been. The most. important single measure is generally believed tơ be the regular emptying of the bowel at shorf intervals of from two to three hours by day and on one or two occasions during the night; this has been recommended regardless of whether the author believed in selective absorption of chloride or back pressure and renal damage, or both, as the cause of the acidosis. Regardless of surgica 5 belief, this advice seems to be good. There is fairly wide agreement, too, that the daily intake of chloride should be restricted, some advoce्êधe merely avoiding the addition of salt to the foo $\mathrm{d}^{+}$ on the plate, while others advise the full rigotis of a 'salt-free' diet. Those who have had thes misfortune to encounter patients with advanced potassium deficiency in addition to acidosiš naturally advocate the regular prophylactic ad $\AA$ ministration of potassium citrate, in addition to some form of chloride restriction. Because their $\bar{B}$ daily output of water is increased most patients? drink more after operation and this natural inclina tion should be strongly encouraged.

Broadly speaking, two explanations of hyper chloraemic acidosis have been proposed. The first ascribes it to selective absorption by the colonic mucosa of chloride from the urine in thes colon. The second explanation invokes impairment of renal function, particularly that of the distal tubules, either by hydronephrosis and back- $\rightarrow$ pressure, especially after the indirect type of anastomosis, or by pyelonephritis and ascending infection, especially after the direct type of anastomosis. Much conflicting evidence has been adduced in support of each of these explanationsw and of combinations of them with other possible mechanisms. As well as the more recent work on the effects of transplantation of the ureters ind dogs and man it seemed worthwhile considering some of the earlier experimental and clinical work, both on transplantation and on intestinap absorption." 
Jacobs and Stirling found that acidosis followed either type of anastomosis, but was rather more common after the direct $(45.5$ per cent.) than the indirect type (32.5 per cent.); this rather small difference in the incidence of acidosis does not seem to implicate particularly either technical procedure. Yet after the direct type of anastomosis 50 per cent. of cases show reflux of air and 30 per cent. reflux of opaque medium from the bowel, whereas after indirect anastomosis there was no evidence of reflux of opaque medium, and of air in only Io per cent. of cases. If back pressure and infection are as important primary factors in the production of acidosis as many authors have claimed, acidosis should be much more common after the direct anastomosis which allows such free access of faeces and gas to the renal pelvis. As there is so little difference in the incidence of acidosis after direct or indirect types of anastomosis, which produce such different organic unions between the ureters and colon, it seems reasonable to conclude that the common primary cause of acidosis lies elsewhere and that absorption from the colon is a more important factor.

It is a general finding that even a short time after transplantation evidence of pyelonephritis can be found in the kidneys and when some years have elapsed there is almost invariably. abundant evidence of chronic inflammation and infection of the kidney, often with signs of hydronephrosis as well (Poole and Cook, I950; Graves and Buddington, 1950). Lapides (1952) has observed pyelographic changes in 77 per cent. of his patients which were often intermittent and improved spontaneously, as were the bouts of acidosis from which his patients suffered. Harvard and Thompson (I95I) reviewed 198 patients whose ureters were transplanted for extrophy of the bladder, of whom 52 per cent. survived 20 years; they attributed 67.5 per cent. of the late deaths to pyelonephritis. Grey Turner (1943) reviewed nine patients between 16 and 30 years after transplantation of their ureters and concluded that after this operation in nearly all cases there was some evidence of ascending infection; eight of these patients were able to work, but five out of six showed marked dilation of the upper urinary tract. He remarked on the general good health of the eight patients he was able to examine; it is difficult to judge how far this was due to the consumption of potassium citrate. Six weeks or more after operation Creevy (1953) found that the plasma chloride concentration was raised in only 44 per cent. of patients whose blood urea concentration was within normal limits, but in 75 per cent. when the blood urea concentration was above normal. In spite of the early onset of infective lesions in the kidneys it is well established that acidosis commonly occurs only intermittently and usually responds rapidly and completely to simple therapeutic measures, even in patients who have signs of moderately severe renal functional impairment.

In an attempt to avoid infection of the renal tract from the colon Baird, Scott and Spencer (1917) transplanted the ureters of dogs into the duodenum; this was apparently followed by the rapid absorption of all the urine, leading to a steady rise in blood non-protein nitrogen and death after a few days. Bollman and Mann (1927) found that the higher they transplanted both ureters into the small intestine the more rapid was the rise in blood urea, although some elevation of the blood urea followed transplantation even into the colon; they found, however, that the concentration of creatinine in the blood did not rise, which suggested that absorption of urinary constituents by the intestine might be selective and that such selective absorption, rather than renal damage, might be the cause of the death of their animals. Jewett (1940) observed that in dogs after transplantation of the ureters to the rectum the blood urea concentration rose if emptying of the bowel was delayed; he also suggested that the accompanying acidosis was due to the absorption of chloride from the bowel and could be prevented by the restriction of the intake of sodium chloride and by the administration of alkali.

Boyce (I95I) has repeated some of this work and shown that the absorption of chloride and nitrogenous material is most active from the caecum and least from the rectum; transplantation of the ureters of dogs to the caecum was associated with a very high mortality rate. Kekwick et al. (I95 I) reported that five out of 15 of their patients died after transplantation of the right ureter to the caecum and the left to the sigmoid colon. They did not find any change in the chloride content of urine which they ran into a caecostomy or an ileostomy in patients with normal kidneys, whose ureters had not been transplanted, and concluded that absorption of chloride from urine in the bowel was not an important factor in the development of acidosis after transplantation of the ureters. These experiments did not reproduce the conditions above a continent anal sphincter under which acidosis arises after ureteric transplantation; indeed in one of their own patients recovery from coma followed the institution of a caecostomy. They attributed the acidosis to back pressure and tubular damage leading to polyuria and chloride retention. Several observers have shown that following intravenous pyelography urine contain- 
ing radio-opaque material may pass freely from the transplanted ureters in the sigmoid colon to the caecum, so that even low anastomosis cannot entirely ensure that the urinary constituents are not presented to higher segments of the colon. There is, however, good experimental evidence in support of the usual practice of transplanting the ureters into the sigmoid colon and sufficient reason for avoiding the small intestine, caecum and right half of the colon.

Absorption from the intestine is an active process and occurs even against a steep concentration gradient. Visscher and his group using $\mathrm{Na}^{24}$ and $\mathrm{Cl}^{3 \theta}$ have shown that even when chloride is being absorbed from a solution containing sodium and chloride in the intestines, $\mathrm{Cl}^{30}$ is passing out of the blood back into the intestine. They found also that there was a high rate of exchange of sodium between the blood and intestinal fluid, the equivalent of all the sodium in the plasma passing into the intestine in 83 minutes; they also found that the colon was more efficient than the small intestine at absorbing sodium and chloride.

Goldschmidt and Dayton (1919) showed that in a dog with a normal serum chloride concentration, chloride was lost into the colon when the colonic chloride content fell below $27.4 \mathrm{mEq}$. per litre; at concentrations above this the quantity of chloride which was absorbed into the plasma varied with the concentration of chloride in the bowel. The magnitude and direction of active transport of an ion across a barrier depends on the balance between the rates of inward and outward migration of a particular ion.

In the case of the colon after bilateral transplantation of the ureters, the quantity of chloride which is absorbed from the urine discharged into the bowel will depend on the concentration of chloride in the original urine and in the plasma, and the length of time the urine is in contact with the colonic mucosa. The chloride content of the body is normally regulated by the kidneys. When all the urine is discharged into the colon absorption of chloride from this urine returns some excreted chloride to the whole body 'pool' of chloride. The urinary chloride concentration is, therefore, likely to rise and unless water intake is increased or chloride intake is reduced this will lead to a vicious circle of rising concentration of chloride in both plasma and the rest of the extracellular fluid and urine.

Bollman and Mann (1927) found that in dogs when only one ureter was transplanted into the bowel chemical changes in the blood did not occur as long as the remaining kidney retained good function (see also Pendleton and West, 1932; Geer and Dragstedt, 1938). This was also observed by Ferris and Odel in surgical patient Some interesting observations after unilaterat transplanation have recently been reported b\$ Parsons et al. (1952). In one patient three times. as much urea and 7.5 times as much chloride: were recovered in 24 hours from the bladdef urine as from the rectal fluid; the creatinine clearance and volume were both about 15 pes cent. less for the rectal fluid compared wit bladder urine, suggesting that although the total output by the transplanted side was less than of the normal side there is a compensatory increas in chloride and urea excretion by the untransplanted side in response to absorption by the colonw In another patient one ureter was transplanted into an artificial bladder formed by isolating the lower sigmoid colon and rectum from the remain der of the bowel by a terminal colostomy. They confirmed the well-known observation thaf whereas the rectal fluid is consistently alkaline the bladder urine is strongly acid; there was also marked reduction in the urea (30 per cent.) chloride (70 per cent.) and sodium (55 per cent. content and volume ( 20 per cent.), but a rise of potassium ( 5 per cent.) content of urine place in the artificial bladder. When $\mathrm{Na}^{24}$ and $\mathrm{Cl}^{308}$ were added to urine which was placed in the artificial bladder the $\mathrm{Cl}^{38}$ concentration of pe्ficis pheral venous blood rose more rapidly than that of $\mathrm{Na}^{24}$ and there was also a disproportionate in the $\mathrm{Cl}^{38}$ content of bladder urine derived from the normal kidney and ureter. These experiment 5 confirm in the human subject the work previousl done on dogs and illustrate as well the rapi excretory response by the normal kidney to the absorption of $\mathrm{Cl}^{39}$ from the urine in the colon In spite of the absorption of sodium from the urine elevation of the serum sodium concentraet tion is not common (ro per cent., Jacobs and Stirling) perhaps because, as Korenberg (195 $\$$ has suggested, the sodium is transferred into cells which have lost potassium.

Berglin (1952) found that in a control subject the intravenous administration of 5 per cent? saline caused only a slight rise in plasma chloride concentration with a marked increase in urinars chloride concentration and output, but that in patient whose ureters had been transplanted there was a rapid rise of plasma chloride concentration which persisted for eight hours, that the urinar\$ chloride concentration also was raised and botbo plasma and urinary chloride concentration fel only slowly towards the normal range. The urinary volume was increased for three hours after the infusion and then fell in spite of an increased intake by drinking. This experimento indicates the reduced capacity of the kidneys to deal with added loads of chloride after transplan 
tation of the ureters, but it does not distinguish between absorption from the colon and renal damage as the causes of this incapacity.

The use of isolated segments of small or large intestine as substitute reservoirs for urine, after excision of the urinary bladder (Bricker, 1950; Glaser, 1952), has the advantage of avoiding the risk of ascending infection and the reflux of faecal material into the ureters and renal pelves.

A short segment (10 in.) of ileum has been used as a conduit from the ureters to the exterior by Annis, Hunter and Wells (1953) and acidosis had not developed in any of their patients. Wilson (1953), however, reported the development of acidosis within 15 days of such an operation which responded to the administration of sodium citrate; as the result of further observations on this patient he suggested that when used in this way the ileum rapidly adapts itself to the new circumstances and the absorption of urinary constituents is then unlikely to occur. Eiseman and Bricker (1952) found that both chloride and urea were absorbed from isolated draining loops of ileum into which the ureters were transplanted, but think that provided the loop is short absorption is unlikely to distort body chemistry. Higgins (1948) found that in dogs when the isolated distal stump of the colon and rectum was used as an artificial bladder it contracted and after two years had almost completely lost its capacity; such shrinkage of the excluded rectum or colon is a well-known sequel to palliative colostomy for inoperable cancers of the bowel. The use of the ascending colon and caecum as a reservoir, with the ileocaecal valve as a sphincter to control discharge of urine from an ileostomy (Moore, 1953) seems unwise in view of the evidence which has been cited. It is too soon to judge whether the use of a short isolated segment of ileum is as safe as has been claimed, the risk of absorption of urinary constituents may have been modified, but it is not certain that it has been eliminated.

In the continent subject urine is secreted against a raised hydrostatic pressure, but it is uncertain how important this elevation of pressure is in the production of acidosis. Shackman (1952) has observed that the elevation of the plasma chloride, which may be associated with acute retention of urine due to prostatic obstruction, subsides spontaneously when the urinary obstruction is relieved; he suggested that transient tubular damage resulted from the raised hydrostatic tension in the urinary tract in acute retention of urine, and that this might be a factor in the production of acidosis after ureteric transplantation.

It is conceivable that disturbance of tubular function could occur simply as the result of back pressure, but it seems unlikely that changes in pressure of the order of a few centimetres of water would have much effect on secretion which depends on the active transport of ions across membrane barriers. It seems unlikely, too, that simple relief of pressure would have much effect on tubular dysfunction, which was due to organic change secondary to bacterial infection. If tubular damage is an important factor in the production of acidosis after ureterosigmoidostomy it is hardly likely to respond as rapidly as is usually the case to relief of pressure such as is afforded by simple drainage of only one kidney by nephrostomy. If there is functional impairment of the distal tubules by back pressure it will surely affect other functions than chloride excretion. The problem could probably be solved by. the catheterization of both ureters after transplantation and the subsequent complete drainage of urine to the exterior, combined with periods of instillation of portions of this urine into the colon.

Chloride is absorbed from the lower colon in excess of sodium, most probably in association with ammonium derived from the bacterial breakdown of urea in the intestine. This disproportionate absorption of chloride with a 'disposable' cation like ammonium will lead to acidosis with depression of plasma bicarbonate concentration In these circumstances the response of the kidneys will be similar to that in experimental acidosis in man induced by the consumption of ammonium chloride (Sartorius et al., 1949); in this state there is a loss of fixed base (chiefly potassium) from the body accompanied by a nearly equivalent quantity of water. Mitchell and Valk (1953) found that acidosis developed in their patients after ureteric transplanation when renal function (as shown by G.F.R., renal blood flow and TMP.A.H.) was better than the normal minimum; they found that when acidosis was corrected the plasma non-protein nitrogen and blood urea nitrogen concentration fell also and concluded that their elevation had been due to the acidosis, to an alteration in rather than to an impairment of, renal function.

When the kidneys attempt to play their normal part in the regulation of chloride and bicarbonate equilibrium, by excreting chloride in the urine, they are foiled for so long as urine is allowed to collect in the colon and rectum, the more chloride that is excreted into the urine the more there is available for absorption by the colon. This vicious circle can be broken by draining away the urine from the colon, thus reducing absorption of chloride and allowing the renal tubules to excrete chloride unhindered by reabsorption and to restore the normal balance of chloride and bicarbonate. The fact that this type of acidosis is so readily and 
completely relieved by continuous drainage of the bowel suggests strongly that organic damage of the tubules or lasting interference with the carbonic anhydrase system in the tubular cells are not important factors in the production of this type of acidosis. There is little evidence of alteration in extracellular base (mainly sodium), but in advanced stages of the hyperchloraemic acidosis there may be some elevation of serum sodium; this may be due to an actual increase in the total quantity of extracellular sodium or merely to an increase in concentration due to reduction in extracellular fluid volume. It is probably unlikely, therefore, that the sum of chloride and bicarbonate is altered, the change being in their proportions.

The total body potassium is reduced as the result of the increased daily loss from the bowel and this is accompanied by a reduction in total body water which chiefly affects the cells since about 98 per cent. of the potassium is intracellular. Disturbances of potassium metabolism which are sufficiently severe to give rise to symptoms are not common. They are most often found after infective lesions or other acute complications. The importance of severe potassium deficiency in association with acidosis is the higher mortality rate, which results from the combination. Although the potassium and other disturbances occur together it is important to appreciate that the mechanisms of production may be quite different. The experiments of Parsons et al (1952) have shown clearly that the higher potassium content of cloacal fluid as compared with that of urine as originally secreted is due to the addition of potassium in the lower sigmoid and rectum. This leads to persistent and progressive loss of base and to a chronic state of intracellular dehydration (Wilkinson, I952), which would account for the inability of these patients to tolerate restriction of their water intake (Kekwick et al., I95I), and for the chronic thirst and salty taste of which many of them complain.

\section{Summary and Conclusions}

The disturbances of blood and body chemistry after transplantation of both ureters to the colon show marked individual variation in severity and time of onset, and some patients appear to survive for many years without significant disturbances. Yet the general impression which emerges from a study of the available reports is remarkably consistent. The commonest feature is elevation of the plasma chloride concentration in a continent patient and this seems to be more common when there is impairment of renal function. It is also a general feature that this type of acidosis responds well and rapidly to such simple treatment as con- tinuous drainage of the bowel with a rectal tube ٌ

The primary change seems to be the absorption $\bar{R}$ of chloride from the colon which causes a moderate elevation of plasma and extracellular chloride con-.centration; to this the kidneys respond by an increased output of chloride in the urine, much? of which, however, may be absorbed from the colon although the net loss from the body is increased. This increased renal excretion is only partially successful in controlling the rising extra- $-\frac{0}{0}$ cellular concentration of chloride, but as thes urinary excretion of chloride approaches a maxi- $\overrightarrow{0}$ mum there is stabilization of the plasma chlorideat a concentration which varies in any individuake from hour to hour according to circumstanceso and intake of chloride in the food. Whether there are changes in the plasma chloride concentration following large increments to, or losses of, chloride from the body depends on the ability of the kidneys to respond by an increase or reduction of chloride output, as may be required. Because् the daily turnover of chloride through the kidneyso is increased so much by absorption of urinary chloride from the bowel the capacity of the kidneys to respond to chloride loading is greatly reduce of after transplantation of the ureters to the colon and the likelihood of elevation of plasma chloride concentration is increased. The renal capacity ofor respond to variations in chloride intake and out tolt may be further reduced by functional impairmento due to hydronephrosis or pyelonephritis; when such organic changes in the kidneys become marked the life of the individual is closely circum scribed by his limited renal capacity and the risk $\$$ of even minor additional complications is seriously $\overrightarrow{6}$ increased.

Alterations in the plasma bicarbonate concen tration are secondary to those in chloride. There is no direct evidence that total plasma or extra을 cellular fluid base concentration is reduced, but in a small proportion of patients plasma sodium concentration is raised and there is evidence that sodium as well as urea and chloride is absorbed from the colon. The continued daily loss of potassium in the bowel leads to a reduction in totab body base and may be the cause of clinicall $P$ evident potassium deficiency and marked intra를. cellular dehydration. After transplantation of both ureters the daily turnover of water is increased by absorption from the colon with other con? stituents of the urine, in the larger volume of water lost each day in the mixed urine and faecese and in the greater quantity drunk; these patients do not react well to changes in their water intake and the more advanced the organic changes in their kidneys the less specific and delicate can bo their renal reaction to changing water an electrolyte intake. 
These patients should be encouraged to eat a full ordinary diet without adding salt to their food at the table, a salt-free diet is unpalatable and unattractive. Instead of restricting their chloride intake it is easier to prescribe a mixture of sodium bicarbonate and potassium citrate, or simply potassium citrate alone; this will counteract the tendency to acidosis and replace the daily loss of potassium in the rectal fluid. They should be advised to drink four to six pints of fluid each day. In ordering their daily life they should seek a dish of herbs and contentment rather than the stalled ox and strife.

\section{BIBLIOGRAPHY}

ANNIS, D., HUNTER, W. R., and WELLS, C. (1953), Lancet, i, 1172 .

BAIRD, J. S., SCOTT, R. L., and SPENCER, R. D. (1917), Surg., Gynec., Obstet., $24,482$.

BERGLIN, T. (1952), Brit. F. Urol., 24, 316.

BOLlman, J. L., and MANN, F. C. (1927), Proc. Soc. Exper. Biol. E' Med., 24, 923.

BOYCE, W. H. (195I), F. Urol., 65, 24 I.

BRICKER, E. M. (1950), Surg. Clin. N. Amer., 30, 151 I.

COFFEY, R. C. (I9I I), F. Amer. Med. Ass., 56, 397.

CREEVY, C. D. (1953), F. Urol., 70, 196.

DIEFENBACH, W. C. L., FISK, S. C., and GIBSON, S. B. (195 I), New Engl. F. Med., 244, 326.

EISEMAN, B., and BRICKER, E. M. (1952), Ann. Surg., 136, 76r. FERRIS, D. O., and ODEL,.H. M. (1950), F. Amer. Med. Ass., 142, 634 .

FLOCKS, R. H. (1949), Ibid., 139, 626.
FOSTER, F. P., DREW, D. W., and WISS, E. J. (1950), Lahey Clin. Bull., 6, 231.

GEER, W. A., and DRAGSTEDT, L. R. (1938), Ann. Surg., I08, 263.

GLASER, S. (1.952), Brit. F. Urol., 24, 216.

GOLDSCHMIDT, S., and DAYTON, A. B. (I919), Amer. $\mathcal{F}$. Physiol., 48, 419.

GRAVES, R. C., and BUDDINGTON, W. T. (1950), f. Urol., $63,26 \mathrm{r}$.

HARVARD, B. M., and THOMPSON, G. J. (195I), Ibid., 65, 223. HIGGINS, C. C. (1948), Ibid., 60, 904.

JACOBS, A., and STIRLING, W. B. (1952), Brit. F. Urol., 24, 259.

JEWETT, H. J. (1940), f. Urol., 44, 223.

KEKWICK, A., PAULLEY, J. W., RICHES, E. W., SEMPLE, R. (1951), Brit. F. Urol., 23, 112.

KORENBERG, M. (195I), F. Urol., 66, 686.

LAPIDES, J. (1952), Surg., Gynec., Obstet., 93, 691.

MITCHELL, A. D., and VALK, W. L. (1953), F. Urol., 69, 82.

MOORE, T. (1953), Lancet, i, 1176.

NESBIT, R. M. (1949), f. Urol., 6r, 728.

PARSONS, F. M., PYRAH, L. N., POWELL, F. J. N., REID, A. W., and SPIERS, F. W. (1952), Brit. F. Urol., 24, 317.

PENDLETON, W. R., and WEST, F. E. (1932), Amer. F. Physiol., I01, 391 .

POOLE, T. L., and COOK, E. N. (1950), F. Urol., 63, 228.

SARTORIUS, O. W., ROEMMELT, J. C.; and PITTS, R. F. (1949), 7. Clin. Invest., 28, 423.

SHACKMAN, R. (1952), Brit. F. Urol., 24, 313.

SIMON, J. (1852), Lancet, ii, 568.

STILES, H. J. (1911), Surg., Gynec., Obstet., 13, 127.

TURNER, G. G. (1943), Brit. med. F., 2, 535.

VISSCHER, M. B., FETCHER, E. S., CARR, C. W., GREGOR H. P., BUSHEY, M. S., and BAKER, D. E. (1944), Amer. $\mathcal{F}$. Physiol., 142, 550 .

VISSCHER, M. B., and ROEPKA, R. R. (1945), Ibid., 144, 468.

VISSCHER, M. B., VARCO, R. H., CARR, C. W., DEAN, R. B., and ERICKSOON, D. (1944), Ibid., I4I, 488.

WILKINSON, A. W. (1952), Brit. F. Urol., 24, 46.

WILSON, A. O. (1953), Lancet, i, 1178.

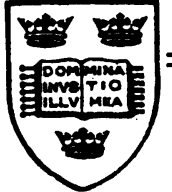

OXFORD MEDICAL PUBLICATIONS

TO BE PUBLISHED THIS MONTH

\section{A PRACTICAL MANUAL OF DISEASES OF THE CHEST}

By MAURICE DAVIDSON, D.M., F.R.C.P.

Consulting Physician to the Brompton Hospital for Consumption and Diseases of the Chest

FOURTH EDITION 658 pages 261 illustrations $\cdot 84 \mathrm{~s}$. net

\section{THE ANATOMY OF THE BRONCHIAL TREE}

By SIR RUSSELL BROCK, M.s., F.R.c.s., F.A.c.s.

Thoracic Surgeon to Guy's Hospital and Surgeon to the Brompton Hospital for Consumption and Diseases of the Chest

SECOND Edition 250 pages 268 illustrations (19 in colour) 45s.net

Selected illustrations suitable for use as a wall chart are available, price 5s. net per packet of 9 plates 